\title{
System Dynamics Modeling for Solid Waste Management in Lima Peru
}

\author{
Margarita Giraldo Retuerto ${ }^{1}$, Dayana Ysla Espinoza ${ }^{2}$, Laberiano Andrade-Arenas ${ }^{3}$ \\ Faculty of Engineering Sciences \\ University of Science and Humanities \\ Lima, Peru
}

\begin{abstract}
This research work focuses on environmental care based on the treatment of solid, organic and inorganic waste. These inappropriate wastes cause deterioration of the environment and the ozone layer. This is why we are currently seeing an abrupt change in climate and diseases caused by environmental pollution. The objective of the research work is to perform a system dynamics modeling for effective and efficient solid waste management in Lima Peru, and thus contribute to the scientific community to achieve a future vision for solid waste management. The methodology used was system dynamics, which made it possible to analyze and understand the behavior of a complex solid waste system in a given time. In addition, vensim software was used for system dynamics modeling, creating the causal diagram and forrester diagram for solid waste management. The results obtained are the system dynamics modeling proposed for solid waste management, which were modeled from 2020 to 2030 , where by 2030 it will be reduced in favorable equilibrium to 23,066 tons. Thanks to this system dynamics modeling, society will be made aware of the need to sort and use solid waste, in order to reduce environmental pollution. Likewise, having a healthy environment that will benefit health, agriculture and education will benefit society as a whole.
\end{abstract}

Keywords-Causal diagram; environmental pollution; forrester diagram; systems dynamics; vensim

\section{INTRODUCTION}

Solid waste management is a major problem worldwide and 90 percent of cities are affected by population growth. The inefficient process of industries, businesses and changing patterns in living standards have increased the generation of solid waste in cities and towns. Solid wastes are those organic and inorganic wastes that are created by the process of transformation, construction or implementation of goods and services. If such solid waste is not handled correctly, it generates environmental pollution and health hazards for individuals [1].

Solid waste includes all waste from humans and animals. From the following, it can be said that solid waste is the consequence of life itself, in a direct way the production of waste. There are several causes, such as improper placement of garbage bins in the city. City Corporation's inadequate waste collection system. More specifically, people are not aware enough to use garbage bins properly [2].

Coastal residents generate the largest proportion of Peru's garbage. In Lima alone, where the largest city is located, home to well over 8 million people, an average of 2,123,016 tons of waste is created each year. Each individual produces approximately 0.61 kilograms per day, which implies a significant increase in solid waste [3]. In Lima Peru in recent years, solid waste has increased aggressively in all corners of the city [4]

Solid waste management is a chain that includes many elements, including proper waste collection, organized transportation, and trained personnel. Proper waste disposal lines and fully automated monitoring systems, and awareness of what the public should and should not do [5]. This is as important as any other survival system in a city like Lima. This paper describes how to use system dynamic modeling as a decision support tool for waste management and planning of the total amount of waste generated in Lima. With more than 9,000 tons, landfills are the most accepted solution for waste disposal. However, improperly selected sites can have many environmental, economic and ecosystemic impacts [6].

To know what a system dynamics is, first of all, This term is often used, even if there are different exceptions. Just as we speak of a system as a way of doing, then we mention that we have a system to solve a problem and achieve a goal [7]. In this way, system dynamics allows the behavior of a solid waste system, how it behaves in a given time. of a solid waste system, how it behaves in a given time. Likewise, system dynamics makes a simulation in years and times and is based on 2 types of diagrams, the casual diagrams and the forrester diagrams, which have their origin in the general theory of systems.

The importance of the research is to contribute to the scientific community to reach a future vision for solid waste management. Under the modeling of a dynamic system. Since there is a lot of pollution from the citizens in Lima Peru.

The objective of this work is to carry out a System Dynamics modeling for the effective and efficient management of solid waste in Lima, Peru.

This paper is structured as follows: In Section II the literature review was performed, in Section III the methodology, in Section IV the results and discussions are shown, finally in Section V the conclusions and future work are presented.

\section{LiterATURE REVIEW}

This section cites solid waste treatment requirements papers and system dynamics modeling papers that continue to engage in research and provides the resources needed to address this work.

According to the author [8], exposes the problem related to sanitary waste and the current management of solid waste treatment. on the other hand, those that can be returned to the production cycle are wasted, this is also known as the 
recovery industry. They represent a direct risk to health and the environment and have hazardous properties such as toxicity, flammability, chemical reactivity, corrosiveness, explosiveness, reactivity, radioactivity.

On the other hand, the author [9], emphasizes that the benefit of good solid waste management can be obtained from many compus, since organic waste decomposes and turns into methane, which is a greenhouse gas. It can also reduce waste in the toilet and increase the service life. It also reduces soil and water pollution.

Likewise, the author [10], synthesizes that informational awareness is useful, since it makes waste segregation possible. In the principles there are significant incidences in the proportion of solid waste. As in sanitary landfills and in the prices associated with the production, disposal and collection of solid waste from households in urban regions.

In this category the author [11], indicates that it can be seen that participants categorize firm waste into plastic, paper and cardboard. In the preparation of products, they use plastic with greater demand and less frequently cardboard and paper, because in this virtual teaching environment the consumption of this material by students has decreased, showing that from home they are strengthening the ecological behavior and good practices of environmental conservation.

Finally, the author [12], states that they have used the systems dynamic model to analyze solid waste. It proposes a long-term solution for new generations with an environmental cultural program that promotes environmental care focused on the recovery of natural resources. Providing education to society based on system dynamics modeling, with casual diagrams and forrester diagrams.

\section{Methodology}

The methodology used is system dynamics, which is a tool for creating simulation models in vensim. This model is used to help visualize temporal behavior in complex environments. It is based on the identification of repetitive sequences in instructions based on causal diagrams and forrester diagrams. In order to develop correctly and thus achieve the objectives, it is applied with formulas and equations shown, in order to be able to run a good model of system behavior based on certain periods. Fig. 1 shows the relationship of system dynamics, consisting of the levels of decision, action and information. They are related to decision functions, flow channels and sources of information.

\section{A. Causal Diagram}

A causal diagram is one that is connected by an arrow that shows the causal relationships and collaborations that variables have with each other [13]. A negative (-) or positive (+) symbol is added to the arrows to indicate the change generated in the dependent variables when the variables change to independent [14].

It is also known as a causal loop diagram, because, within each type of loop, it turns in the same direction as the loop it belongs to, and this could be clockwise or counterclockwise [15]. It is worth mentioning that a correctly applied causal diagram is beneficial for the construction and analysis of a

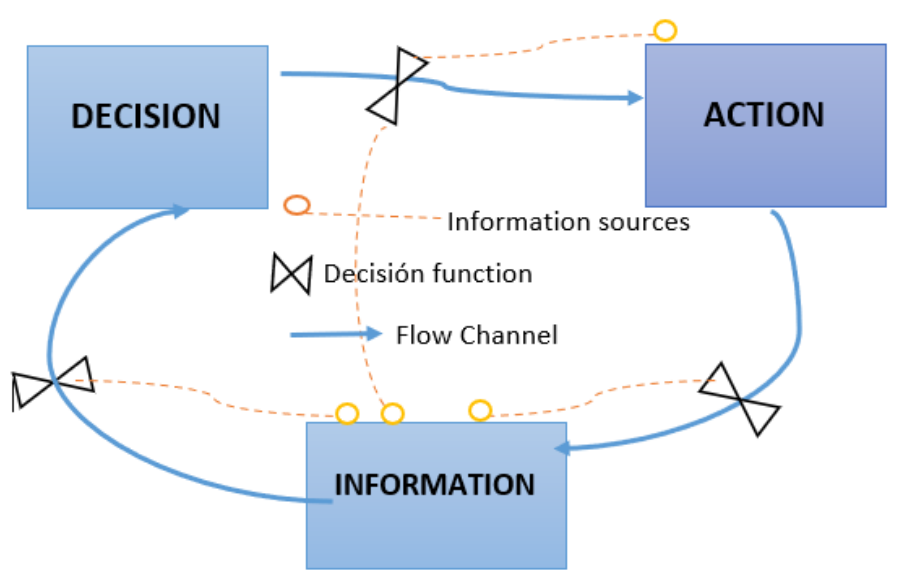

Fig. 1. Dynamic of Systems.

real system, since it can help in the planning and processes of a system [16].

After the above mentioned causal diagram, we put into practice with the following Fig. 2, which shows that, with an increase in the population, there is a growth in the proportion of waste produced.Similarly, as a result of systematic collection, the proportion of garbage collection has increased. The proportion of solid waste in landfills increases due to the impact on the environment. It will increase pollution and generate deterioration of the quality of life and population growth.

The stress created by the growth, the proportion of waste caused by the people, means that they must collect a larger proportion of waste. This will make it possible to minimize the proportion of waste, if there is a lower proportion of the population for collection. This leaves us with little collection capacity to cope with population growth and the waste that everyone leaves behind simply because they live.

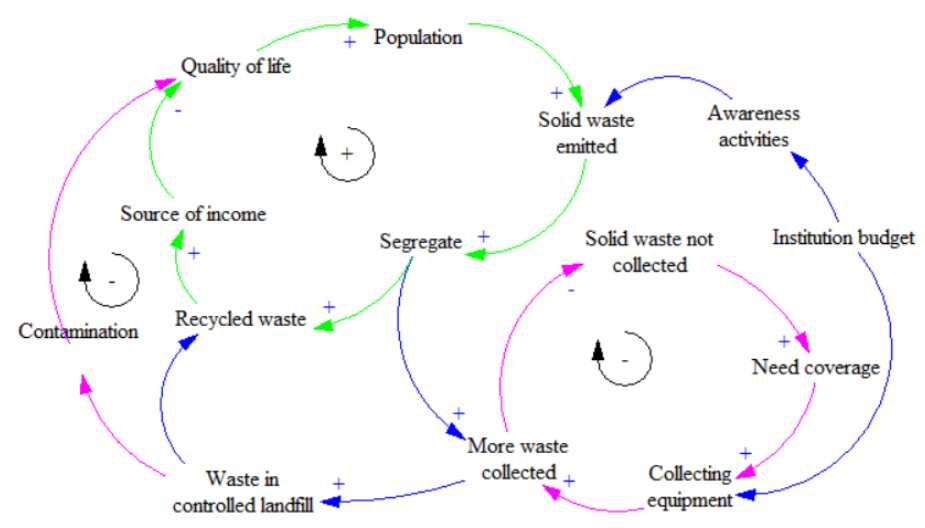

Fig. 2. Solid Waste Management System Causal Diagrama [1].

\section{B. Forrester Diagram}

In this section, the causal diagram seen in Fig. 1, already once classified the resources that appear in changing state, flows and auxiliaries. From the causal diagram was used to make the Forrester Diagram, with the required data. 
In addition, the behavior of the solid waste system is being analyzed through the causal diagram and the forrester diagram using the data, equations and mathematical formulas of the system that is being developed. Among the attributes that make up the modeling of the system, there are also the well-known feedback loops [17].

We use system dynamics to represent or transform the interaction of these effects into dynamical systems that help create the behavior. It assigns values and limits based on data collected from existing systems, using formulas that describe the type and strength of all interrelationships between sets of changes.

Therefore, the vensim program was used to plot the interactions of influence and by means of the forrester diagram of the solid waste, the specifications of the mathematical equations were provided [18]. Looking at the flow diagram and inventory of Forester's solid waste diagram in Fig. 3, the whole system under study can be seen and some conclusions can be drawn.

First there is the fact that the three huge primitive feedback loops are being suppressed. This provides clear guidance on how to proceed if one part of the relevant change set has changed. Not only does it affect other parts of the system, but changes after some time will affect the same variable that caused the change [19].

\section{Equations}

Table I shows in summary form the sets of equations of the variables and parameters of the three level variables for the system dynamics modeling results.

1) variable level: : They are those that assume an accumulation in time and vary with other variables of system states, called flows. They characterize the pattern of the general population, the amount of solid waste on the streets.

2) Variable flow:: Variable flow: they explicitly manifest the alteration of the time units of the levels. The flow variable feeds or decreases the grade, determining the variations in levels. As well as birth variables, deaths, incoming waste, recycled waste, uncollected waste and collection [20].

3) Auxiliary variables and constants:: They suggest changing help in the model and are based on collaborating with the flow variables within the model and representing them in graphs, with the following level variations of solid waste modeling. Determined by variations in environmental quality, leachate emission, gas emission, contamination, amount of waste generated, source of income, recycling.

\section{Data}

Table II shows the data used in the forrester diagram for the graphs of waste generated, total recycling. Also for the controlled landfill waste graph that was made in the vensim tool.

\section{RESUlt AND Discussion}

\section{A. About Modeling}

The system dynamics model allows the behavior of a complex system.To assist in decision making, whether tactical,
TABLE I. FORMULAS [1]

\begin{tabular}{|c|c|}
\hline Variables & Formulas \\
\hline $\begin{array}{l}\text { Variable } \\
\text { Level }\end{array}$ & $\begin{array}{l}\text {-Population = Births - Deaths } \\
\text {-Amount of waste in the streets = IF THEN ELSE (Waste not collected } \\
\text { - Collection.. } \\
\text {-Waste in controlled landfill = Incoming waste - Recycled waste. }\end{array}$ \\
\hline $\begin{array}{l}\text { Variable } \\
\text { flow }\end{array}$ & $\begin{array}{l}\text {-Births }=\text { Population } * \text { Growth rate. } \\
\text {-Deaths }=(\text { life expectancy }+ \text { Quality of life }) * \text { Population. } \\
\text {-Incoming waste }=(\text { Collection }+ \text { Amount of waste collected }) *(1- \\
\text { Utilization Rate }) . \\
\text {-Recycled Waste }=\text { Waste in Controlled Landfill } * \text { Recycled Waste } \\
\text { Rate. } \\
\text {-Waste not collected }=\text { Segregation }- \text { Recycling }- \text { Waste collected. } \\
\text {-Collection = Quantity of collection equipment } 2 * \text { Truck capacity } 2 \\
* \text { Collection frequency } 2 .\end{array}$ \\
\hline $\begin{array}{l}\text { Auxiliary } \\
\text { and } \\
\text { constant } \\
\text { variables }\end{array}$ & $\begin{array}{l}\text {-Collection = Amount of collection equipment } 2 * \text { Truck capacity } 2 \\
* \text { Collection frequency } 2 . \\
\text {-Emission of leachate }=\text { RANDOM UNIFORM }(0.01,0.1,0.001) . \\
\text {-Contamination = (Leachate Emission }+ \text { Gas Emission }) * \text { Waste in } \\
\text { Landfill. } \\
\text {-Quantity of waste generated = Population * Solid waste generation } \\
\text { rate-Sensitized population. } \\
\text {-Quantity of collected waste = (Number of collecting equipment } * \\
\text { Truck capacity } * \text { Collection frequency. } \\
\text {-Source of income = Average Price } * \text { Total recycled. } \\
\text {-Recycled = Segregation * Recycling rate. }\end{array}$ \\
\hline
\end{tabular}

TABLE II. DATA

\begin{tabular}{|l|l|}
\hline Num & Data \\
\hline 1 & -Truck capacity $=2600$ \\
2 & -Truck capacity $2=2600$ \\
3 & -Average Price $=0.5$ \\
4 & -Budget $=395000$ \\
5 & -Realization rate $=0.2$ \\
6 & -Growth rate $=0.013$ \\
7 & -Solid waste generation rate $=1.17$ \\
8 & -Recycling rate $=0.2$ Units: $\mathrm{Kg} /($ day $*$ person) \\
9 & -Rate of Recycled Waste from the Dump $=0.09$ \\
\hline
\end{tabular}

strategic and policy design; how to act in a general system to drive it towards the desired behavior. The structure of the system dynamics modeling was built on causal diagrams and forrester diagrams. From the variables and data required by the system.

In addition, vensim software was used to create causal and forrester diagrams for system dynamics modeling for solid waste. Since Vensim is a software that allows simulation to improve the system performance and model quality [21].

Fig. 4, 5 and 6 show the notation of the values of the three scenarios, with their respective line graphs as: Equilibrium scenario, which are the red lines and are numbered 2, favorable scenario, which are the green lines and are numbered 3, and unfavorable scenario, which are the blue lines and are numbered 1 .

In Fig. 4, the activity of the sub-variables is shown. Residuals are unavoidable in all situations. The results of the equilibrium scenario are used as a reference for the behavior of the solid waste produced. As expected, the movement tends to be greater than the balance in the opposite scenario. By 2022, the volume of industrial waste will reach 12,270 , tons. On the other hand, the growth rate of waste generated tends to be low in favorable scenarios. On the other hand, the growth rate of waste generated tends to be low in favorable scenarios. 27.03 


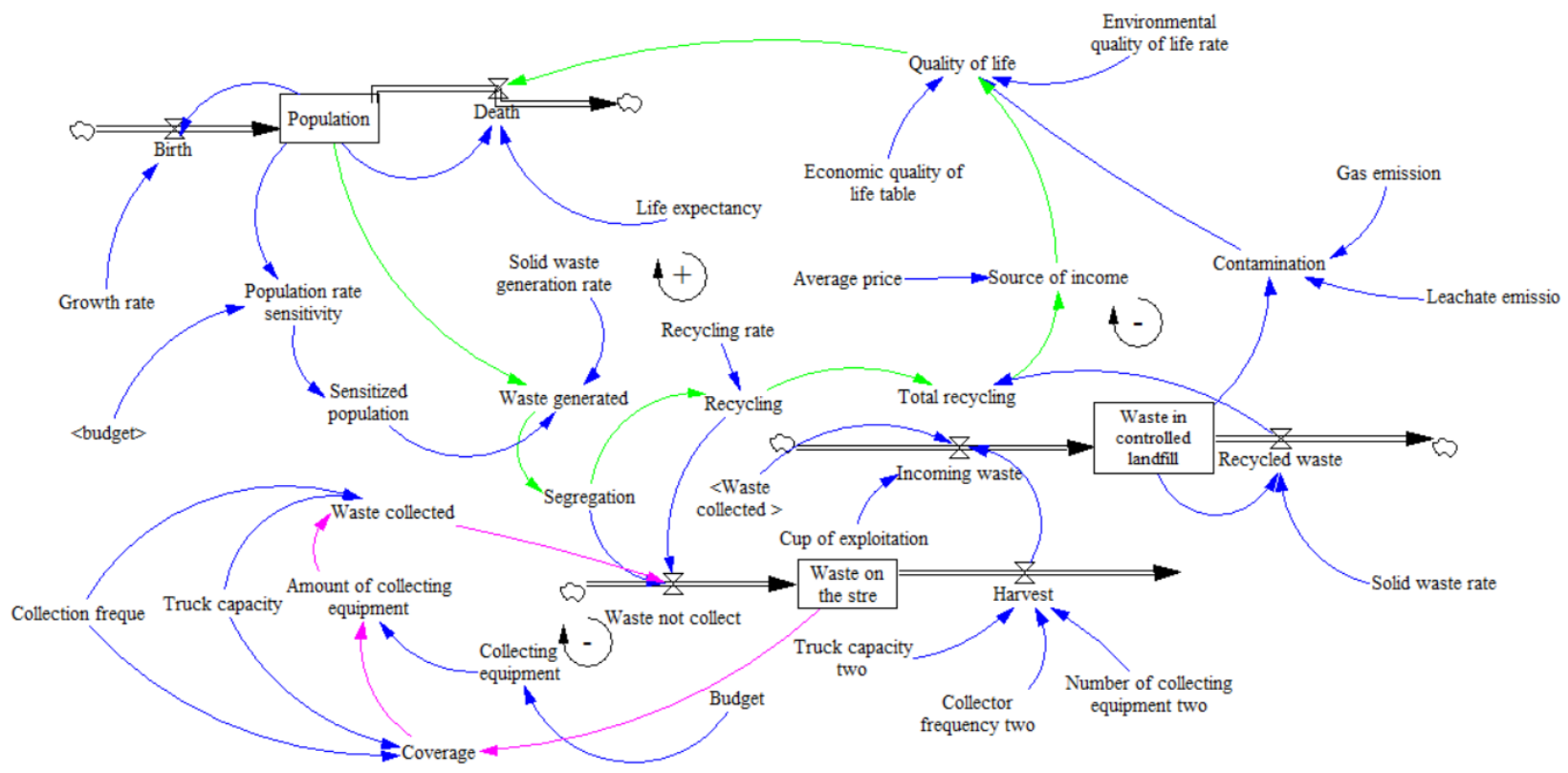

Fig. 3. Solid Waste Management System Forrester Diagram[1].

tons in 2023.

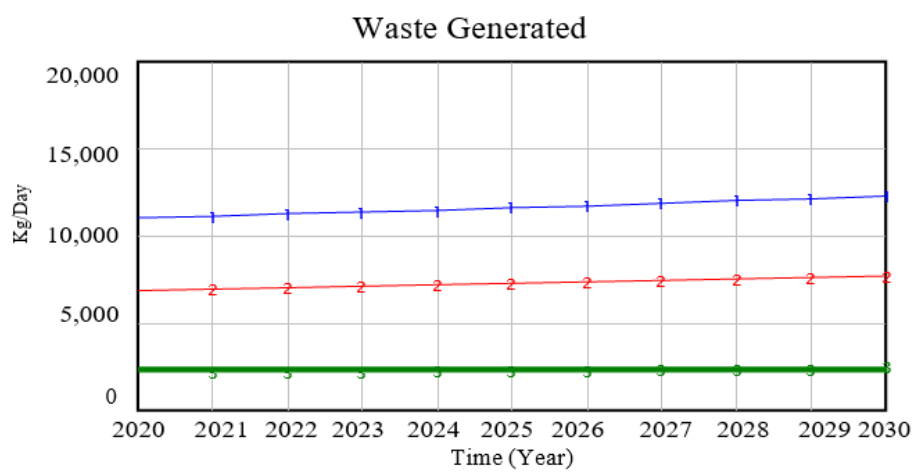

Fig. 4. Waste Generated.

Fig. 5 below shows the behavior of the secondary variables and waste recycling in each scenario. Here it can be seen that solid waste generation has a direct impact on recycled waste. The result of the balanced scenario serves as a benchmark for the rest of the performance [22]. In the unfavorable scenario, the behavior has a high growth trend, due to the growth of waste, reaching $6,429.56$ tons of recycled waste in 2024. In the favorable scenario, the behavior has a trend that preserves in a stable degree with respect to the Equilibrium scenario, the rate of recycled hard waste will reach 2668 tons in 2024.

The following Fig. 6 shows the behavior of the variables at the level of solid waste at the landfill in metropolitan Lima. Here we will observe the behavior of the direct influence of the waste generated and the waste recycled from the population. In the unfavorable scenario, as expected, there is a growing trend, where rigid waste in the landfill increases significantly. Reaching 55,078 tons of waste by 2025 . While in the favorable scenario it has a less increasing behavior. Landfilled solid waste is managed to be significantly reduced compared to the
Total Recycling

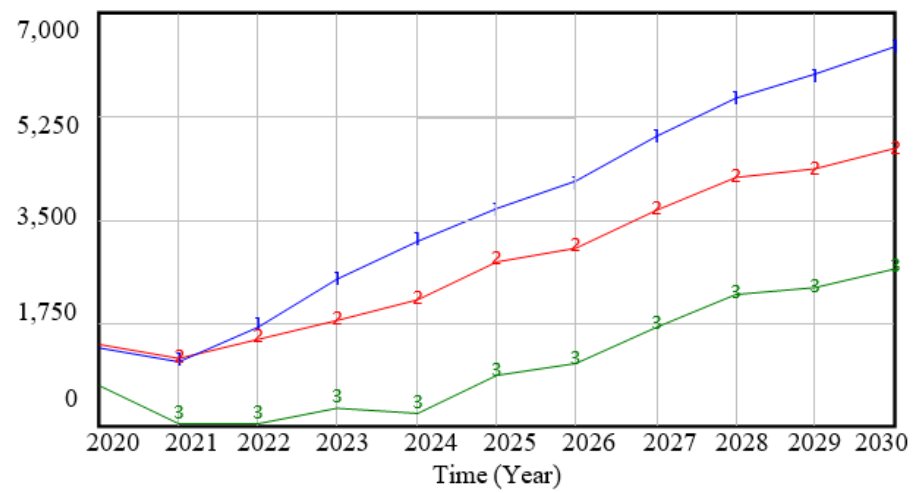

Fig. 5. Total Recycling.

equilibrium scenario. By 2026, the amount of solid waste in landfills will be 21,033 tons.

Similarly, by 2030, the proportion of solid waste will be reduced in a favorable balance to 23,066 tons.

\section{B. About the Methodology}

For the discussion section, the tool comparison tables are shown. Used for the development of a system. Depending on the methodology applied in the work of the system. Table III shows the comparison between two important methodologies. System dynamics is a methodology for analyzing and modeling the temporal behaviors of complex environments [23]. It is based on the identification of feedback loops between resources, such as information and document delays in the system. On the other hand, Design Thinking is a methodology that considers exploration and thinking as fundamental as intuition in solving problems. 
Waste in Controlled Landfill

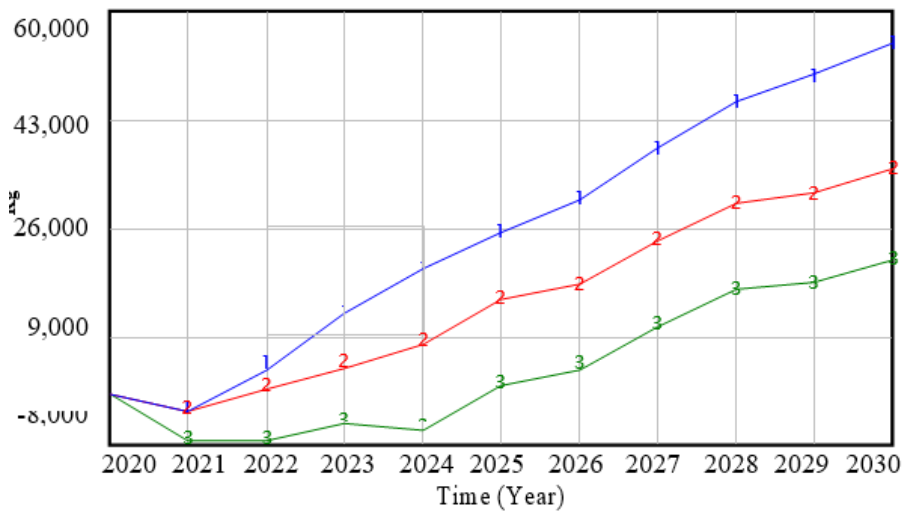

Fig. 6. Waste in Controlled Landfill.

TABLE III. DynamiC OF Systems-Design THINKING

\begin{tabular}{|l|l|}
\hline Dynamic of systems & Design thinking \\
\hline Allows entry and exit to a jurisdiction. & $\begin{array}{l}\text { You have creativity, elaboration, and } \\
\text { learning through trial and error. }\end{array}$ \\
\hline $\begin{array}{l}\text { Line of ordered products. \& He con- } \\
\text { stantly works in multidisciplinary teams. }\end{array}$ \\
\hline $\begin{array}{l}\text { Maximum power and very good volume } \\
\text { of use. \& Apply to achieve tangible and } \\
\text { consistent results. }\end{array}$ \\
\hline $\begin{array}{l}\text { Inventory management is very good be- } \\
\text { cause there is only one for each line See. } \\
\text { \& It greatly enhances the competitive } \\
\text { strategy of companies. }\end{array}$ \\
\hline
\end{tabular}

Table IV shows the comparison of the Vensim and Powesim studio software tools. Vensim is a simulation software developed by Ventana Systems. Primarily supports continuous simulation, with various agent-based and discrete-event modeling capabilities [24]. On the other hand, we have the powersim studio software, which is a fully equipped simulation model development environment, which makes it easy for you to create and perform analysis and simulation runs.

TABLE IV. VENSIM-POWERSIM STUdIO

\begin{tabular}{|l|}
\hline Vensim \& PowerSim studio \\
\hline It is a simulation tool in which it sim- \\
ulates a dynamic model of systems. \& \\
It is a software library, which is used in \\
applications that include simulation in \\
Windows applications. \\
\hline Provides a simple way to create sim- \\
ulation models (diagrams, flowcharts). \\
$\&$ Create models and perform fully \\
equipped analysis. \\
\hline It is useful to simulate a projection of \\
growth, population of certain markets. \\
$\&$ Provides multi-user simulation game \\
creation. \\
\hline
\end{tabular}

The comparison between the vensim software and the powerSim studio is that both do system modeling. The comparison between the vensim software and powerSim studio is that both do systems modeling. That is why the comparison is made that the vensim software allows to simulate and plot causal diagrams and forrester diagrams, a case that powerSim studio does not. In addition, the vensim software performs studies and forecasts of different scenarios with sensitivity analysis, using mathematical functions, such as data, equations and is very dynamic, user-friendly and acceptable to the public, it has many advantages. On the other hand, the powerSim studio studio, while it is true that it is very old, also does modeling, but it is a little more limited. That is why the comparison is made to see why the vensim software was used more and why not the other software that are similar to it, such as PowerSim studio, stella among others.

\section{COnClusions And Future Work}

In conclusion, the system dynamics modeling allowed us to have a holistic view of the problem and thus provide a proposal for good management of solid waste from the authorities in Lima, Peru, which were modeled from 2020 to 2030. Thanks to these system dynamics modeling showed that environmental pollution will slowly reduce and will benefit society to raise awareness and sort solid waste, so as to have a healthy environment.

With respect to the methodology, system dynamics was used to analyze and understand the behavior of solid waste. Also, with the help of the vensim tool, it was possible to create a simulation of the models based on the causal diagram and forrester diagram for solid waste management.

One limitation of the research work is that it was not possible to contact the authorities in order to interview them about the solid waste problem and also to make a qualitative analysis of it. As a future work, it is suggested that it be complemented with a comparative study of the different countries of South America with respect to solid waste. Also explore the use of other modeling software such as Stella, powersim and Dinamo.

\section{REFERENCES}

[1] F. A. Condor Paucar and E. L. Lima Ataucusi, "Modelo prospectivo para el manejo de los residuos sólidos del distrito de pampas de la provincia de tayacaja," 2017.

[2] T. S. Vasagade, S. S. Tamboli, and A. D. Shinde, "Dynamic solid waste collection and management system based on sensors, elevator and gsm," in 2017 International Conference on Inventive Communication and Computational Technologies (ICICCT), 2017, pp. 263267.

[3] F. A. Condor Paucar and E. L. Lima Ataucusi, "Prospective model for the management of solid waste from the district of pampas of the province of tayacaja," 2017.

[4] S. Zeeshan, Z. Shahid, S. Khan, and F. A. Shaikh, "Solid waste management in korangi district of karachi using gps and gis: A case study," in 2018 7th International Conference on Computer and Communication Engineering (ICCCE), 2018, pp. 1-4.

[5] A. Popov and A. Kuzmina, "Justification of the common information space components for the solid waste management," in 2018 IEEE International Conference"Management of Municipal Waste as an Important Factor of Sustainable Urban Development" (WASTE), 2018, pp. 25-27.

[6] S. Zeeshan, Z. Shahid, S. Khan, and F. A. Shaikh, "Solid waste management in korangi district of karachi using gps and gis: A case study," in 2018 7th International 
Conference on Computer and Communication Engineering (ICCCE), 2018, pp. 1-4.

[7] J. C. Hadiwibowo, S. Halim, B. N. Yahya, K. Agustin, and I. H. Sahputra, "A policy strategy evaluation for covid-19 pandemic in the city of surabaya using vensim ventana dynamic system simulation," in $20213 \mathrm{rd}$ East Indonesia Conference on Computer and Information Technology (EIConCIT), 2021, pp. 215-221.

[8] D. J. Gamarra Parra and J. e. L. Sanabria Gamboa, "Strategies for the use of organic solid waste a in the production on of renewable energy in colombia," 2020.

[9] M. B. G. Wegener, I. Buxeda, A. y Malmquist, and I. Anders y Herrera, "Polygeneration systems 'o $\mathrm{n}$ in the á urban area: advantages and disadvantages today," in XIII CTV 2019 Proceedings: XIII International Congress of Virtual City and Territory: "Challenges and paradigms of the contemporary city”: UPC, Barcelona,October 2-4, 2019. Center de Politica de Sol i Valoracions, CPSV / Universitat Polytechnic, 2019.

[10] F. A. Condor Paucar and E. L. Lima Ataucusi, "Prospective model for the management of solid waste from the district of pampas of the province of tayacaja," 2017.

[11] J. S. Y. Vicente, M. R. V. Tomás, D. M. H. Acha, and M. D. B. De La Cruz, "Ecological behavior and environmental culture, fostered through virtual education in students from lima-peru," Revista de ciencias sociales, vol. 27, no. 1, pp. 385-398, 2021.

[12] "Solid waste management models: literature review," in 2018 2nd International Conference on Smart Grid and Smart Cities (ICSGSC).

[13] N. M. Sagar del Campo and L. Zamora-Matamoros, "Graphical methods in biomedical causality research," Electronic magazine Dr. Zoilo E. Marinello Vidaurreta, vol. 44, no. 4, 2019.

[14] V. Tower, "Analysis of variations in inventories through the causal diagram, case study construrama-tubyco de martínez," in INTERDISCIPLINARY ENGINEERING CONGRESS 'I AS, 2017, p. 26.

[15] C. F. Naranjo Viteri, "Reconstrucción del concepto de alienación en marx desde la dinámica de sistemas," B.S. thesis, PUCE, 2017.
[16] V. D. G. Vera and J. C. G. Vera, "Seguridad informática organizacional: un modelo de simulación basado en dinámica de sistemas," Scientia et technica, vol. 22, no. 2, pp. 193-197, 2017.

[17] C. Estay-Ossandon and A. Mena-Nieto, "Modelling the driving forces of the municipal solid waste generation in touristic islands. a case study of the balearic islands (2000-2030)," Waste management, vol. 75, pp. 70-81, 2018.

[18] F. A. Condor Paucar and E. L. Lima Ataucusi, "Prospective model for the management of solid waste from the district of pampas of the province of tayacaja," 2017.

[19] N. Phonphoton and C. Pharino, "A system dynamics modeling to evaluate flooding impacts on municipal solid waste management services," Waste Management, vol. 87, pp. 525-536, 2019.

[20] X. Meng, Z. Wen, and Y. Qian, "Multi-agent based simulation for household solid waste recycling behavior," Resources, conservation and recycling, vol. 128, pp. 535545, 2018.

[21] E. Korchagina and O. Shvetsova, "Analysis of environmental consequences of tourism activity in baikal lake area: Regional practice of solid waste management," in 2018 IEEE International Conference"Management of Municipal Waste as an Important Factor of Sustainable Urban Development" (WASTE), 2018, pp. 19-21.

[22] N. P. Adriyanti, A. Gamal, and O. C. Dewi, "Solid waste management models: Literature review," in 2018 2nd International Conference on Smart Grid and Smart Cities (ICSGSC), 2018, pp. 37-40.

[23] S. A. H. Morales and L. Andrade-Arenas, "Inventory management analysis under the system dynamics model," International Journal of Advanced Computer Science and Applications, vol. 12, no. 1, 2021. [Online]. Available: http://dx.doi.org/10.14569/IJACSA.2021.0120174

[24] R. R. A. Marreros, K. V. N. Dionisio, L. A. R. Tuanama, J. A. Q. Gutarra, and L. AndradeArenas, "Study of post-covid-19 employability in peru through a dynamic model, between 2020 and 2025," International Journal of Advanced Computer Science and Applications, vol. 12, no. 1, 2021. [Online]. Available: http://dx.doi.org/10.14569/IJACSA.2021.0120171 